\title{
A Systematic Approach of Data Fusion Technique in RFID Sensor Network using Neuro-Fuzzy Technique
}

\author{
Sujata Kundu \\ Narula Institute of Technology, \\ Kolkata, W. B., India
}

\author{
Chayan Ranjit \\ Egra S. S. B. College, \\ Purba Medinipur 721429, W. B., India
}

\begin{abstract}
In this paper, a systematic approach is used for sale prediction in a multistoried retail business with the help of multi sensor data fusion technique using Neural Network and Fuzzy Logic. This method can better solve problems existing in traditional sale prediction which are basically depends on the personal experience. In this work a 3-layers data fusion structure is used. In this system, the sale data experiential characteristic and the sale data-fitting characteristic are fused by fuzzy inference system to get sale prediction. After using the Feed Forward Back Propagation algorithm, the system is trained for predefined target value and then the system calculate the sale statistic in runtime which is fused with the data of expert databases using fuzzy logic technique.
\end{abstract}

\section{Keywords}

Radio Frequency Identification (RFID), Data Fusion, Artificial Neural Network (ANN), Fuzzy Logic Technique.

\section{INTRODUCTION}

The work discussed in this paper is based on Radio Frequency Identification (RFID) technology and data fusion technique to identify the recent trend and the sale statistic of a departmental store using Artificial Neural Network (ANN) \& Fuzzy Logic. The technique could also be applied to predict the seasonal sales of the items in large retail business. The specific items in the departmental store are tagged with passive RFID tags i.e., each of item receives a unique identity number on entering the store and are kept on a particular zone in the multi storied departmental store. It is assumed that each floor of the store is divided into number of zones and depending on the market values of the items, they are placed in appropriate floor. The items of same type with similar market value are kept at the same floor in multistoried departmental store. The number of RFID readers in each zone of the departmental store depends on the size of the zone and the reading/ interrogating range of the RFID reader. RFID readers track the items continuously in their respective zones and periodically send that information to the application to take appropriate decisions. The problem of systematic \& periodic monitoring of the items in the departmental store is addressed in this application so that the demands, locations and distributions of every item in the store can be invigilated with intelligence. The proposed application is successfully demonstrated on a simulated case study.

\section{RELATED WORK \& MOTIVATION}

Most of the research works regarding data fusion in wireless sensor network is done by proposing new energy efficient routing protocols to improve and increase the lifetime of sensor network. Much of the work is also done towards data aggregation technique to increase the sensor node battery life time thereby improving the lifetime of a sensor network.

M. Demirbas [1] presented a feasibility study of monitoring large public building using wireless sensor networks, where some of the open research problems regarding data fusion describe in [2]. P. Manjunatha, et al [3] presented a multisensor data fusion technique in cluster based using fuzzy logic for reducing false fire alarm rate. Aircraft dry bays and fire detection system in engine compartment is proposed in [4], where the authors used a fuzzy inference system to detect a fire. Dempster-Shafer and Bayesian data fusion approach are describe in [5][6]. In [7][8][9][10][11][12] the works focused on object identification using data fusion and image analysis technique. A multi-level approach in Sensor fusion is described in [13][14][15][16]. The work in [17], [18] proposes fire detection system using neural network and fuzzy inference system. Most relevant work [19] is the D-FLER, fuzzy logic engine for rule based wireless sensor network. The model considers only two parameters to detect an event. Chair and Varshney [20] proposed a data fusion algorithm for local decision-making by using the minimum probability of error criterion. To implement the rule, for each sensor the probability of false alarm and the probability of detection must be known, but this information is not always available in practice.

Alessandra Orsoni et al. [21] presented a data fusion, based on cashier's receipts and several aggregate indicators, for trend identification in large retail business using fuzzy technique. Hong Bao et al. [22] presented a fire detection system based on intelligent data fusion technology. Fabio Campos et al. [23] presented an extended approach of dempster-shafer theory. T. Germa et al. [24] presented vision and RFID data fusion for tracking people in crowds by a mobile robot.

\section{ARTIFICIAL NEURAL NETWORK- A BRIEF INTRODUCTION}

An Artificial Neural Network (ANN) [25], usually called Neural Network (NN), is a computational model or mathematical model that is inspired by the structure as well as functional aspects of biological neural networks. The aim of ANN is to copy the human capability to adjust in the current environment and to change according to the circumstances. Artificial Neural Networks [26] consists of many nodes, i.e. processing unit analogous to neurons in the brain. It is an information processing system by which the elements, neurons can process the information. By the connection links the signals are transmitted. All the links are associated with individual weights, which are multiplied with the incoming signals for the network. The output signal can be obtained by applying the activations to the input. The neural network can generally be a single or a multi-layer network. Normally an ANN is an adaptive system which can change its structure on the basis of internal or external information by the learning phase during the flows through the network. Modern neural networks are also known as non-linear statistical data modeling tools which can be used to model complex relationships among the inputs and outputs or to find patterns in the data. Thus Artificial Neural Network represents 
the major extension to computation. They performed the operation similar to that of the human brain.

Hence it is reasonable to except a rapid increase in the understanding of artificial neural networks leading to improve network paradigms and a host of application opportunities.

There are two basic types of Artificial Neural Networks, namely

\section{i) Artificial Neural Network with feedback}

ii) Artificial Neural Network without feedback

The input values can be traced back by the output values in the networks with feedback. However in the network without feedback, for every input vector laid on the network, an output vector is calculated and this can be read from the output neurons. Networks having only a forward flow of information are called feed forward networks. One of the most important types of feed forward networks is Back Propagation Networks. Back propagation is a systematic method for training multilayer artificial neural networks. It has strong mathematical background using extend gradient-descent based delta learning rule. It provides an efficient method to change the weight in a feed forward network, with differentiable activation function units (here Binary Sigmoidal Function is used), to learn a training set of input-output values. Because of the gradient descent method it can minimize the total squared error of the output computed by the network which is trained by supervised learning method. The main purpose of this network is to train the net to achieve a balance between the ability to responds correctly to the input patterns that are used for training and the ability to provide good responds to the input that are similar.

\subsection{Training Algorithm}

$\mathrm{x}$ : Input training vector

$\mathrm{x}=\left(\mathrm{x}_{1}, \mathrm{x}_{2}, \ldots, \mathrm{x}_{\mathrm{n}}\right)$

$\mathrm{t}$ : Output target vector

$\alpha$ : Learning rate

$\delta_{\mathrm{k}}$ : Error at output unit $\mathrm{y}_{\mathrm{k}}$

$\delta_{\mathrm{j}}$ : Error at hidden unit $\mathrm{z}_{\mathrm{j}}$

$\mathrm{V}_{0 \mathrm{j}}$ : bios on hidden unit

$\mathrm{Z}_{\mathrm{j}}$ : Hidden unit $\mathrm{j}$

$\mathrm{W}_{0 \mathrm{k}}$ : bios on output unit $\mathrm{k}$

$\mathrm{Y}_{\mathrm{k}}$ : Output unit

The training algorithm of back propagation involves four stages, viz.

Initialization of Weights:

Step1: Initialize weight to small random number.

Step2: While stopping condition is false, do Steps 3-10

Step3: For each training pair do Steps 4-9

Feed Forward

Step4: Each input unit receives the input signals xi and transmits these signals to all units in the layer

above i.e. hidden units.

Step5: Each hidden unit $\left(\mathrm{z}_{\mathrm{j}, \mathrm{j}}=1,2, \ldots, \mathrm{p}\right)$ sums its weighted input signals

$$
\mathrm{z}_{-\mathrm{in} \mathrm{j}}=\mathrm{v}_{\mathrm{oj}}+\sum_{\mathrm{i}=1}^{\mathrm{n}} \mathrm{x}_{\mathrm{i}} \mathrm{v}_{\mathrm{ij}}
$$

Applying activation function

$$
\mathrm{Z}_{\mathrm{j}}=\mathrm{f}\left(\mathrm{z}_{-\mathrm{in} \mathrm{j}}\right)
$$
i.e. output unit.

and send this signal to the unit in the layer above

Step6: Each output unit $\left(\mathrm{y}_{\mathrm{k}}, \mathrm{k}=1,2, \ldots, \mathrm{m}\right)$ sums its weighted input signals

$$
\mathrm{y}_{-\mathrm{ink}}=\mathrm{w}_{\mathrm{ok}}+\sum_{\mathrm{j}=1}^{\mathrm{p}} \mathrm{z}_{\mathrm{j}} \mathrm{w}_{\mathrm{jk}}
$$

Applying activation function

$$
\mathrm{Y}_{\mathrm{k}}=\mathrm{f}\left(\mathrm{y}_{- \text {in } \mathrm{k}}\right)
$$

Back Propagation of Errors:

Step7: Each output unit $\left(\mathrm{y}_{\mathrm{k}}, \mathrm{k}=1,2, \ldots, \mathrm{m}\right)$ receives a target patterns corresponding to an input

patterns, error information term is calculated as

$$
\delta_{\mathrm{k}}=\left(\mathrm{t}_{\mathrm{k}}-\mathrm{y}_{\mathrm{k}}\right) \mathrm{f}\left(\mathrm{y}_{-\mathrm{in} \mathrm{k}}\right)
$$

Step8: Each hidden unit $\left(\mathrm{z}_{\mathrm{j}}, \mathrm{j}=1,2, \ldots, \mathrm{p}\right)$ sums its delta inputs from units in the layer above

$$
\delta_{-i n j}=\sum_{\mathrm{k}=1}^{\mathrm{m}} \delta_{\mathrm{j}} \mathrm{w}_{\mathrm{jk}}
$$

The error information term is calculated as

$$
\delta_{j}=\delta_{-i n j} \mathrm{f}\left(y_{-i n ~ j}\right)
$$

Updating of Weight and Biases:

Step9: Each output unit $\left(\mathrm{y}_{\mathrm{k}}, \mathrm{k}=1,2, \ldots, \mathrm{m}\right)$ updates its bias and weights $(j=0,1, \ldots, p)$

The weight correction term is given by

$$
\Delta \mathrm{W}_{\mathrm{jk}}=\alpha \delta_{\mathrm{k}} \mathrm{z}_{\mathrm{j}}
$$

And the bias correction term is given by

$$
\Delta \mathrm{W}_{0 \mathrm{k}}=\alpha \delta_{\mathrm{k}}
$$

Therefore,

$$
\mathrm{w}_{\mathrm{jk}}(\text { new })=\mathrm{w}_{\mathrm{jk}}(\text { old })+\Delta \mathrm{W}_{\mathrm{jk}}, \mathrm{w}_{0 \mathrm{k}}(\text { new })=\mathrm{w}_{0 \mathrm{k}}(\text { old })+
$$
$\Delta \mathrm{W}_{0 \mathrm{k}}$

Each hidden unit $\left(z_{j}, j=1,2, \ldots, p\right)$ updates its bias and weights $(\mathrm{i}=0,1, \ldots, \mathrm{n})$

The weight correction term

$$
\Delta \mathrm{V}_{\mathrm{ij}}=\alpha \delta_{\mathrm{j}} \mathrm{x}_{\mathrm{i}}
$$

The bias correction term

$$
\Delta \mathrm{V}_{0 \mathrm{j}}=\alpha \delta_{\mathrm{j}}
$$

Therefore $\mathrm{v}_{\mathrm{ij}}$ (new) $=\mathrm{v}_{\mathrm{ij}}$ (old) $+\Delta \mathrm{V}_{\mathrm{ij}}$, $\mathrm{v}_{0 \mathrm{j}}($ new $)=\mathrm{v}_{0 \mathrm{j}}($ old $)+\Delta \mathrm{V}_{0 \mathrm{j}}$

Step10: Test the stopping condition. 


\section{PROPOSED SYSTEM MODEL}

In this work, the multistoried departmental store has been assumed and is divided into three floors, where each floor is divided into several zones (as in the figure 1), and each zone is equipped with passive RFID readers with a built-in ZigBee transceiver. The readers in each zone are capable of constantly monitoring the tagged items present in their respective zones. It is also assumed that there is a single entry and exit point present in the store that are equipped with RFID readers.

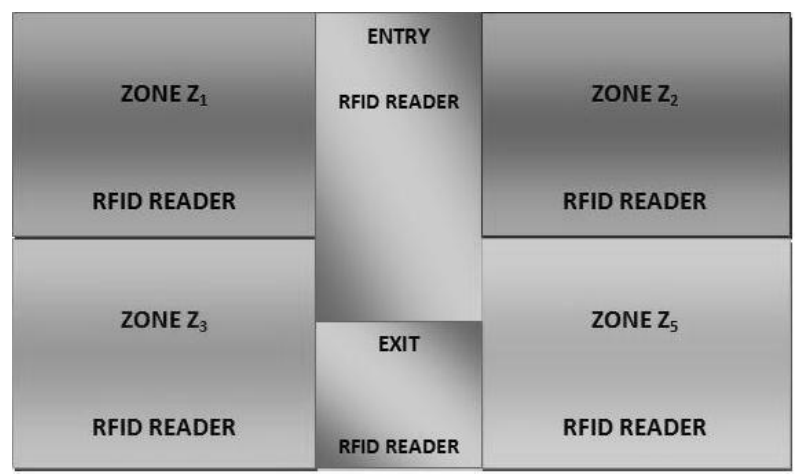

Figure1: Structure of zones in each floor

\subsection{Assumption}

The following assumptions are made to implement the proposed system:

The multistoried departmental store is divided into three floors where each floor divided into four zones.

The multistoried departmental store has different types of items that are placed at its proper rack in appropriate floor i.e., at each zone in each floor there are several racks, which are used to store the item of same type and almost same market value.

While entering to the store each item will be attached with a passive RFID tags and each tag will contain information regarding their identity, which can be described in terms of a record of 9-tuples (TypeOfTheProduct, SubTypeOfTheProduct, Product-ID, Position, ManufactureDate, ExpireDate, Price, Weight, and DateOfEntry)

The RFID readers are placed in the strategic positions of each zone in the departmental store to automate the identification process and send the information of the items to the application.

In this work the passive RFID tags are used for minimizing the cost of the system.

The readers have different radio ranges. So the amount of reader need to monitor the items spanned over entire zone in the departmental store is depended upon the size of the zone in each floor and the radio range of readers. Consider the radio range of RFID reader of the proposed system is at least 50 meters.

All the items are monitored by their respective reader of each zone. So the Reader is capable of detecting the presence of all items within its neighborhood at that particular zone. The presence or disappearance of a tagged item from a particular zone located in the command room is automatically reported to the server. In this server the database is stored and also here the application software is running.

Communication between the RFID readers and the server built with the help of the ZigBee transceiver and the selfconfiguring network topology.
The readers gather information of the items of their respective zones in particular floor and send that information periodically to the application to predict the monthly sale, seasonal sale, total sale and that help to take appropriate decisions.

\subsection{Flow Chart of the Proposed System:}

The functionality of the proposed system has been described by the following flow chart:

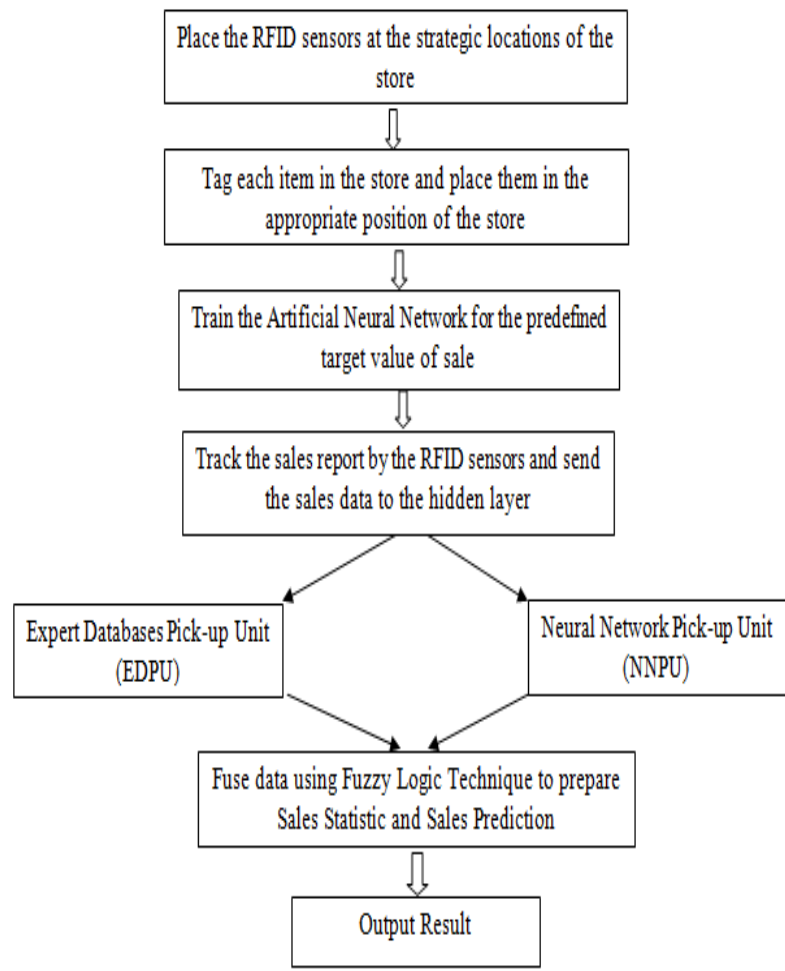

Flowchart showing the proposed solution strategy

\section{METHODOLOGIES USED FOR THE PROPOSED SYSTEM IMPLEMENTATION}

\subsection{Data Fusion Framework For Sales Detection}

\section{a) Overview}

Sales of a multistoried departmental is usually classified into high, medium or low depending on the number items sold and their respective market values e.g. as the market value of ornaments are higher than the grocery items, therefore the effective sale of the store will be increased at a very high rate if the ornaments are sold in a large volume than those of grocery items. Also there are some other environmental conditions such as weather, humidity, wedding season, electronics goods urgency, movie, sports and other man made activity that may affect the sale statistics of multistoried departmental store. Hence the sales detection is more difficult task than other classical signal detection. 


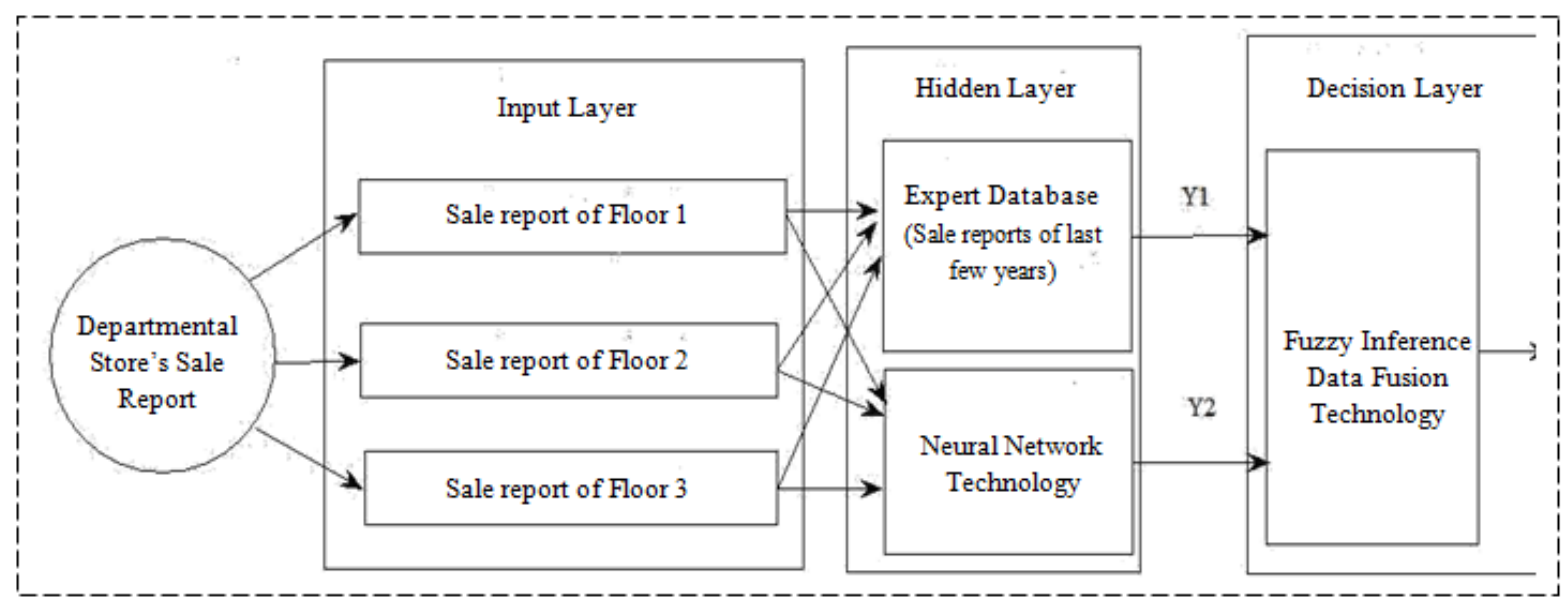

Figure2: The 3-layer data fusion structure of sale detection

\section{b) Sale detection characteristic based on data fusion:}

Data fusion technology is a new method in sales detection to improve detection accuracy, to eliminate infection of disturbance and to overcome time-varying and aging of items in the departmental store. Structure model of data fusion is usually classified into parallel, serial, detract and tree-like type. In the work the reader data are fused based on the parallel and distributed structure of the different functional components of the systems which is described in fig. 2 .

The effective sales detection and prediction system has three data fusion layers: the input layer, the middle/hidden layer and the output/decision layer.

The Input layer collects and processes the data primarily at very beginning stage.

The middle layer picks up the sales data from the input layer for filtering and analysis of raw data.

The decision layer fuses the various sale characteristics from the second layer and makes a decision related to sales probability.

At first Input layer collects the sales data from three floors and then processes it initially and send them to the Middle layer.

The Middle layer in this system extracts the sales data sent through the Input layer by means of the expert-database pickup unit (EDPU) and the neural network pickup unit (NNPU). The System looks up the expert database with the initial sale report from the Input layer to predict the corresponding sale of that season. Last few years' sale experts' reports are stored in the expert data bases.

But for the data without any information in the expert database may have greater error in sale prediction. In those cases Neural Network Technology (as in figure 3) has great advantage. So for those data that does not have any past reference, sales detection is executed by the Neural Network Technology.

The NNPU is a three layers Back Propagation (BP) neural network with the step varying Back Propagation learning algorithm. It adjusts the weight and threshold values of the neural network by making the sum-squared error between fact output and expected output least. In Input layer of the Artificial Neural Network Technology, there are three inputs which are the numbers of item sold with respect to the total item from floor 1, 2 and 3. In the hidden layer of the Artificial Neural Network Technology, there are three nodes and only one node in decision layer which responds to the sale datafitting characteristics Y2. The weight matrix between Input layer and Hidden layer is W1 and weight matrix between Hidden layer and Decision layer is W2.

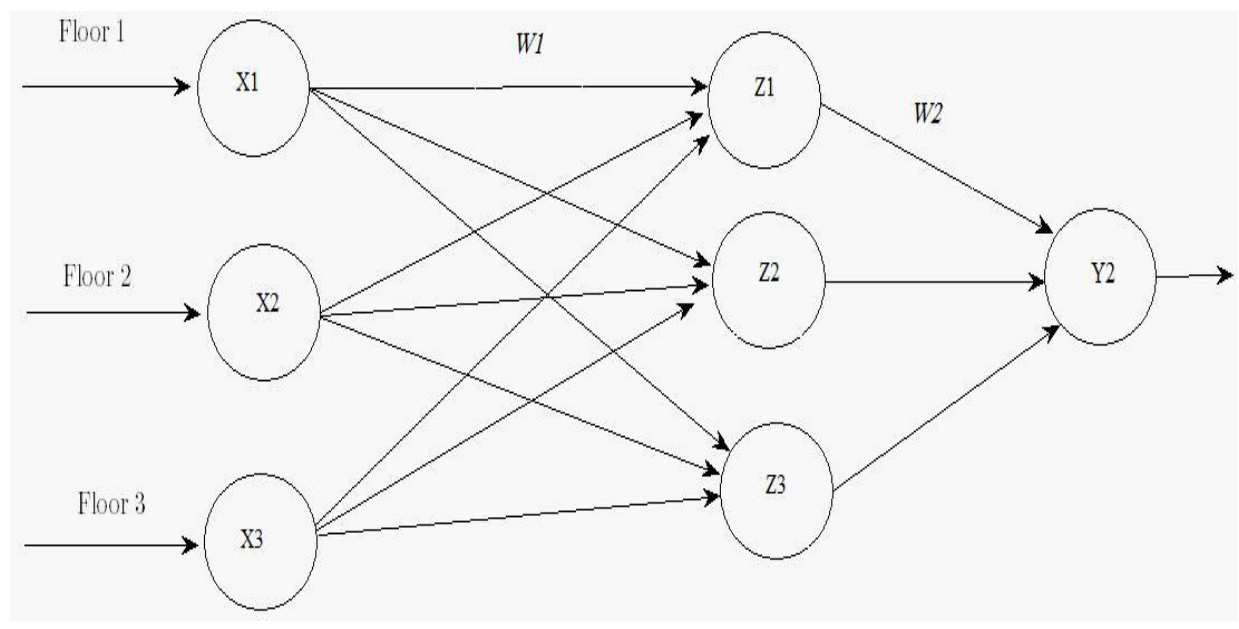

Figure3: The structure of Neural Network Technology 


\section{EXPERIMENT AND RESULT}

According to the known experimental data, the training samples have been selected to train the neural network. After training, the neural network can be seen as a model of the sale data-fitting characteristic. To ensure the completeness, the training samples need to include those data that have a large

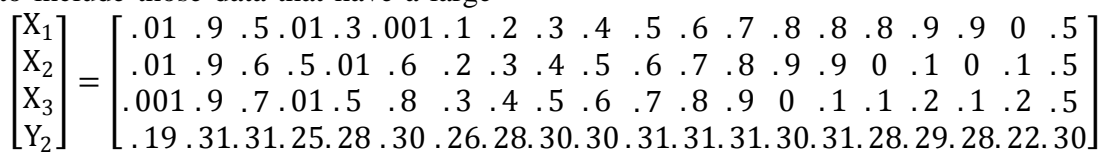

Where initial input matrixX $=\left[\begin{array}{llll}0.6 & 0 & .8 & 0.0\end{array}\right]^{\mathrm{T}}$, target $\mathrm{t}=0.30$ with learning rate $\alpha=0.5$.

The 1st Hidden layer initial weight matrix $\mathrm{W}_{1}=\left[\begin{array}{lll}3 & 2 & 5 \\ 3 & 2 & 5 \\ 3 & 2 & 5\end{array}\right]$, and after training $\mathrm{W}_{1}=\left[\begin{array}{lll}2.93 & 1.79 & 4.99 \\ 2.90 & 1.72 & 4.99 \\ 3.00 & 2.00 & 5.00\end{array}\right]$

The 2nd Hidden layer initial weight matrix $\mathrm{W}_{2}=\left[\begin{array}{l}4 \\ 3 \\ 3\end{array}\right]$, and after training $\mathrm{W}_{2}=\left[\begin{array}{c}1.02 \\ 0.23 \\ -0.03\end{array}\right]$

The 1st Hidden initial bias matrix $\mathrm{W}_{01}=\left[\begin{array}{l}0 \\ 0 \\ 1\end{array}\right]$ and after training $\mathrm{W}_{01}=\left[\begin{array}{c}-0.12 \\ -0.35 \\ 0.99\end{array}\right]$.

and 2nd Hidden initial bias matrix $\mathrm{W}_{02}=[1]$ and after training $\mathrm{W}_{02}=[-2.03]$.

In the Decision layer the sale prediction is implemented by fuzzy inference data fusion technology. It sends the sale data characteristic obtained by the Neural Network Technology and the experience characteristic output from the Expert Database to a fuzzy inference data fusion system, where they are fused. The fuzzy system is capable of processing unsure information and implements the fusion inference in term of the two characteristics to obtain the final system output. A change rate, or in the special areas where the maximum or minimum is, and the data that can denotes the behavior of this system in details. Based on above predefined characteristics, 20 set of results after training samples are selected and the result shows in the following:

fuzzy system makes as similar an inference as a human being does, thus greatly reduce the wrong sale prediction.

\section{Fuzzyfication:}

The fuzzyfication is the process of transforming crisp values into fuzzy linguistic variables. The membership function can be used to associate the grades to each of the linguistic variable. Selection of the number of the membership functions and their initial values are depends upon the process knowledge and the intuition. A membership function has value between 0 and 1 over an interval of crisp variable. This function can vary to provide the resolution needed. If the number of input membership functions increases the number of rules can grow exponentially.

In this sale prediction algorithm $\mathrm{Y} 1$ and $\mathrm{Y} 2$ are the input fuzzy variables and the sale prediction is the output variable. The membership functions VERY-LOW, LOW, AVERAGE, HIGH and VERY-HIGH are defined for input variable Y1 and Y2 and VERY-LOW, LOW, AVERAGE, MODERATE, HIGH, VERY-HIGH and ULTRA-HIGH are defined for output variable.

Fig. $4 \& 5$ show the membership graph for input variables Y1 and Y2 respectively where fig. 6 shows that for output variable "Result". In the example, the fuzzy VERY-LOW, LOW, AVERAGE, HIGH and VERY-HIGH are defined as trapezoidal, triangular, triangular, triangular and trapezoidal membership functions respectively.

Membership function plot

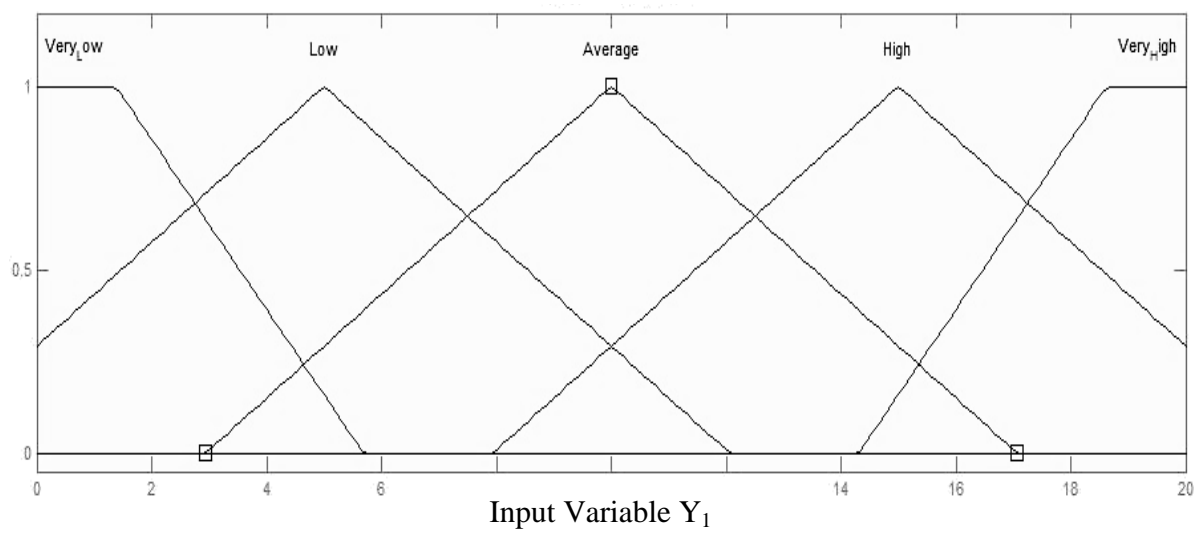

Figure4: Membership function for the input variable $Y_{1}$ 


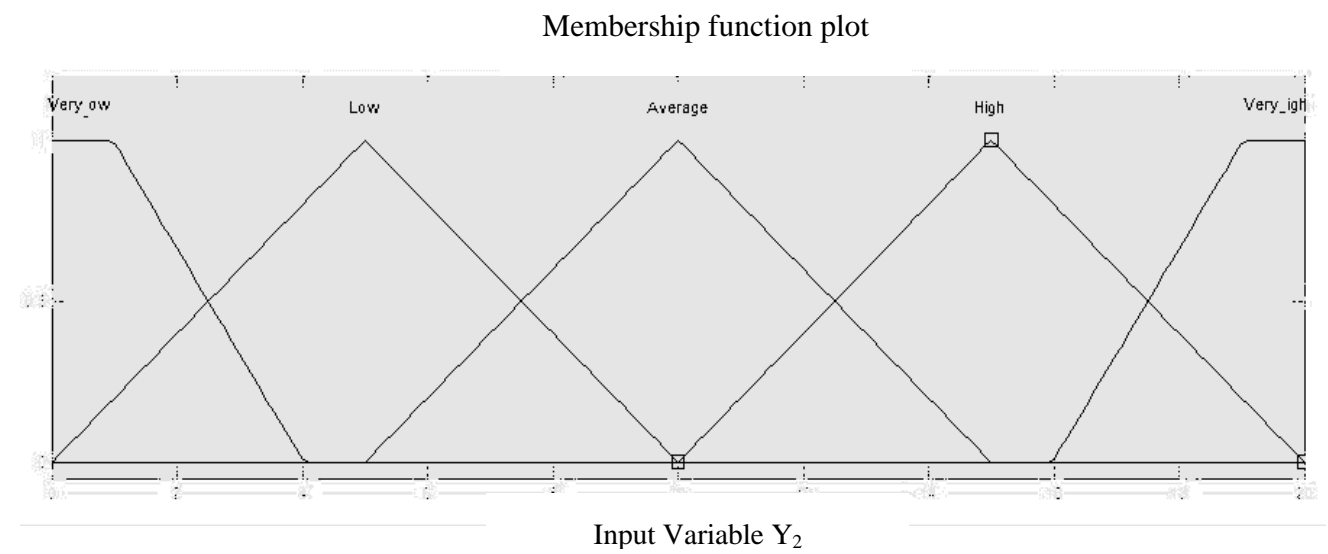

Figure5: Membership function for the input variable $\mathrm{Y}_{2}$

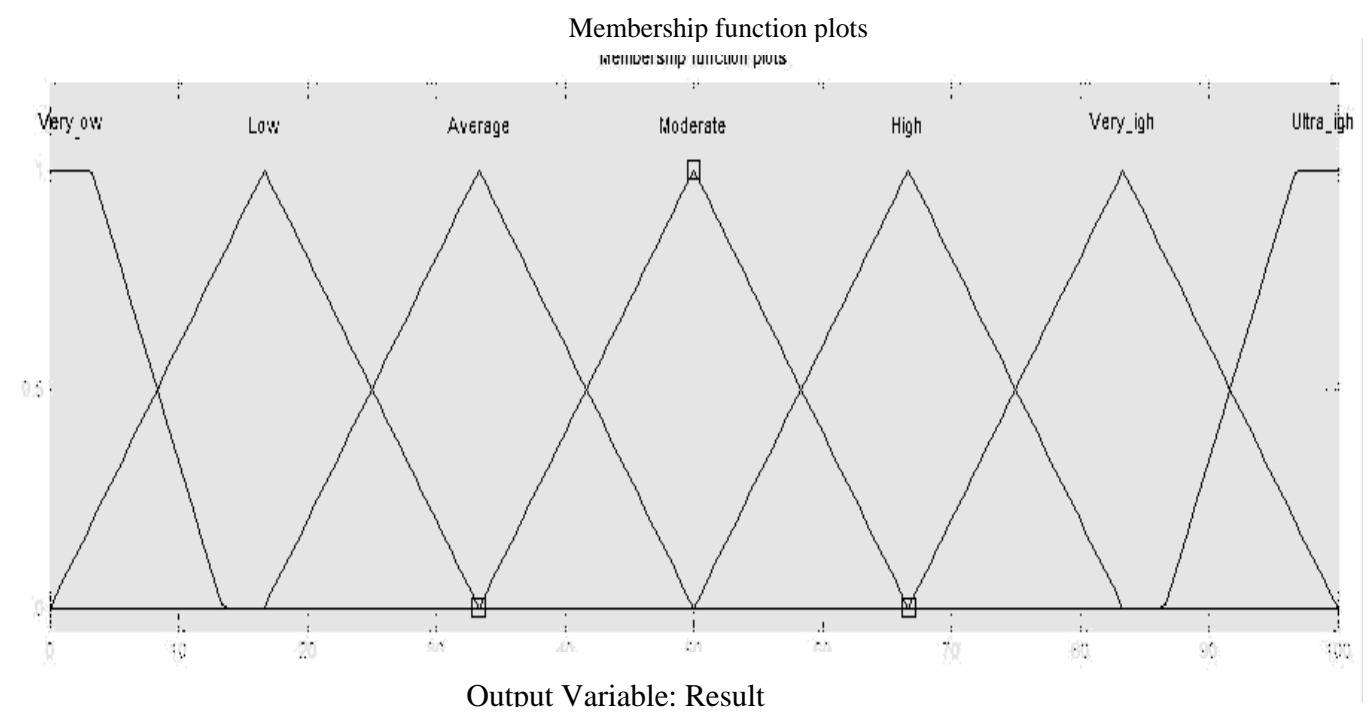

Figure6: Membership function for the output variable "Result"

\section{Fuzzy Inference System:}

This system consists of fuzzy rules (IF antecedent THEN consequent) that are devised by an expert knowledge base system or through the input-output learning system. Gaussian, triangle, and trapezoid functions are the most commonly used membership functions. Triangular and trapezoidal-shaped membership functions are used for the variables to simplify the computations in the fuzzy rules.

Core of the fuzzy system is this rule base system which mimics human reasoning.

Mamdani method is the most commonly used fuzzy inference technique. Fuzzy rule base drives the inference system to generate fuzzy outputs, which can be defuzzified to get system outputs.

The Fuzzy if-then rules in expert system are usually in the following form:

If (Y1 is Very Low) and (Y2 is Very Low) then (Sale Prediction is Very Low)

If (Y1 is Very High) and (Y2 is Very High) then (Sale Prediction is Ultra High)

If (Y1 is Average) and (Y2 is Average) then (Sale Prediction is Average)

If (Y1 is Average) and (Y2 is High) then (Sale prediction is Moderate) and so on. 

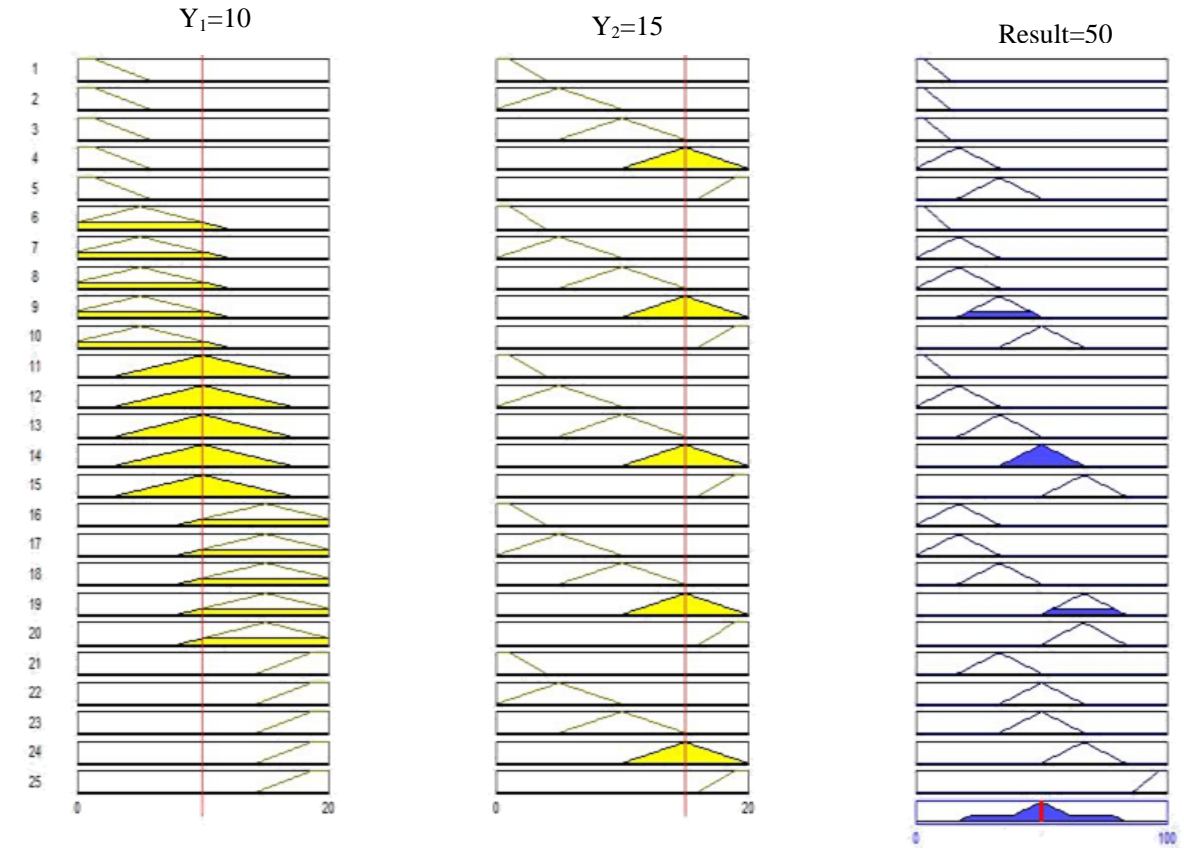

Figure7: Membership functions and sample fuzzy calculation for sale probability

The rules are created using the Fuzzy Inference System (FIS) editor contained in the Matlab Fuzzy Toolbox [27].

\section{Defuzzification:}

The transformation from a fuzzy set to a crisp number is called defuzzification. There are many kinds of defuzzification methods, usually maximum membership and centroid techniques are used.

Fig 7 to 8 shows a sample fuzzy calculation of a sale prediction and surface based on the input variables $\mathrm{Y} 1$ and Y2. Here defuzzification is done using centroid method.

It is given by the following formula:

$\mathrm{z}^{*}=\frac{\int \mu_{\mathrm{A}}(\mathrm{z}) * \mathrm{zdz}}{\int \mu_{\mathrm{A}}(\mathrm{z}) \mathrm{dz}}$

Where $\mu_{A}(z)$ is the membership function of set A.

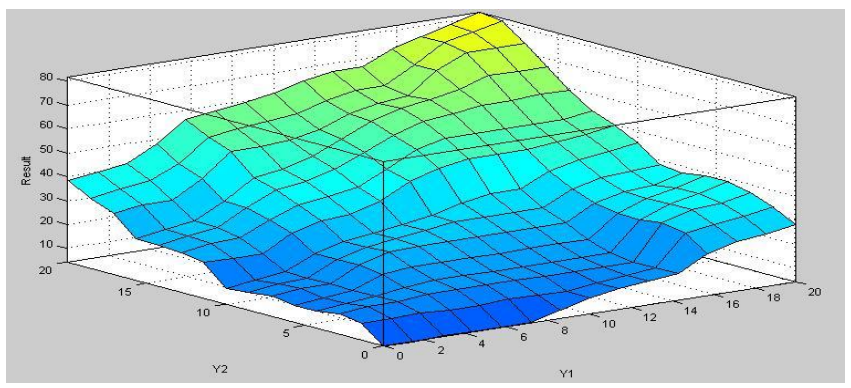

Figure 8: Surface view of the sale probability

\section{CONCLUSION}

In this paper, a data fusion technique using neural network and fuzzy logic approach is proposed for sale detection and prediction in a departmental store scenario. The problem of systematic and periodic monitoring of the items in a departmental store can be handled with a minimum number of readers placed in a strategic location of the store. This type of applications monitored only the tagged items rather than monitoring the entire store. The proposed fuzzy logic approach effectively handles the uncertainty and vagueness present in the environment data with low false prediction rate. Also the proposed data fusion method improves the accuracy of sale prediction by processing multiple sensors data collected from different floor of the store. More accurate, useful and comprehensive information can be gathered by deploying sensors at multiple points in the store. The rules can be easily adjusted and modified based on the environmental parameters.

\section{REFERENCES}

[1] M. Demirbas, "Wireless sensor networks for monitoring of large public buildings," Department of large public buildings," Department of Buffalo, SUNY Buffalo, NY, Tech. Rep., 2005

[2] D. Hall and A. Garga, "Pitfalls in Data Fusion (and How to Avoid Them)", Proceedings of the Second International Conference on Information Fusion (Fusion '99), pp. 429-436, 1999.

[3] P. Manjunatha, A.K. Verma and A. Srividya, "MultiSensor Data Fusion in Cluster based Wireless Sensor Networks Using Fuzzy Logic Method”, IEEE Region 10 Colloquium and the Third ICIIS, Kharagpur, INDIA December 8-10.,2008

[4] Y. Simon, "A fuzzy logic approach to fire detection in aircraft dry bays and engine compartments," IEEE Transaction on Industrial Electronics, vol. 47, no. 5, pp. 1161-1171, Oct 2000

[5] Y.C. Ho, (1964) A Bayesian approach to problems in stochastic estimation and control, IEEE Trans. Automatic Control AC-9, 333

[6] J. Braun, (2000) Dempster-Shafer theory and Bayesian reasoning in multisensor data fusion, Sensor Fusion: Architectures, Algorithms and Applications IV; Proceedings of SPIE 4051, 255-266 
[7] D.J. Kewley, (1992) Notes on the use of DempsterShafer and Fuzzy Reasoning to fuse identity attribute data, Defense Science and Technology Organization, Adelaide. Technical memorandum SRL-0094-TM.

[8] M. A. Simard, and et al. (2000) Multisource information fusion applied to ship identification for the Recognized Maritime Picture, Sensor Fusion: Architectures, Algorithms and Applications IV; Proceedings of SPIE $4051,67-78$

[9] S. Schwartz, (2000) Algorithm for automatic recognition of formations of moving targets, Sensor Fusion: Architectures, Algorithms and Applications IV; Proceedings of SPIE 4051, 407-417

[10] J. Triesch, (2000) Self-organized integration of adaptive visual cues for face tracking, Sensor Fusion: Architectures, Algorithms and Applications IV; Proceedings of SPIE 4051, 397-406

[11] F. Cremer, and et al. (October 1998) Sensor data fusion for antipersonnel land mine detection, Proceedings of EuroFusion98, 55-60

[12] M. Cooper, M. Miller, (1998) Information gain in object recognition via sensor fusion, Proceedings of the International Conference on Multisource-Multisensor Information Fusion (Fusion '98), 1, 143-148

[13] D. Str"omberg, (2000) A multi-level approach to sensor management, Sensor Fusion: Architectures, Algorithms and Applications IV; Proceedings of SPIE 4051, 456461

[14] H. Myler, (2000) Characterization of disagreement in multiplatform and multisensor fusion analysis, Signal Processing, Sensor Fusion, and Target Recognition IX; Proceedings of SPIE 4052, 240-248

[15] Yi Zou, Ho Yeong Khing, Chua Chin Seng, Zhou Xiao Wei, (2000) Multi-ultrasonic sensor fusion for autonomous mobile robots, Sensor Fusion: Architectures, Algorithms and Applications IV; Proceedings of SPIE 4051, 314-321

[16] M. Kokar, and et al (2000) A reference model for data fusion systems, Sensor Fusion: Architectures, Algorithms and Applications IV; Proceedings of SPIE 4051, 191-202

[17] Z. B. Li and H. Zhou, "Research on the application of fuzzy data fusion to cable fire detecting system," in
Proceedings of the Third International Conference on Machine Learning and Cybernetics, vol. 4, Shanghai, Aug 2004, pp. 2083-2085

[18] H. Bao, J. Li, X. Zeng, and J. Zhang, "A fire detection system based on intelligent data fusion technology," in Proceedings of the Third International Conference on Machine Learning and Cybernetics, vol. 2, Nov 2003 pp. 1096- 1101

[19] M. Marin-Perianu and P. Havinga, D-FLER A Distributed Fuzzy Logic Engine for Rule-Based Wireless Sensor Networks, ser. Lecture Notes in Computer Science. Berlin / Heidelberg: Springer, Nov 2007, vol. 4836/2007, pp. 86- 101

[20] I. Chair and P. Varshney, "Optimal data fusion of correlated local decisions in multiple sensor detection systems," IEEE Transactions on AES, vol. 28, no. 3, pp 916-920, 1992.

[21] A. Orsoni et al.," Data Fusion for Trend Identification in Large Retail Business using Fuzzy Technique", 14th European Simulation Symposium A. Verbraeck, W. Krug, eds. (c) SCS Europe BVBA, 2002

[22] H. Bao, et al., "A Fire Detection System Based on Intelligent Data Fusion Technology", the Second International Conference on Machine Learning and Cybernetics, Xi", 2-5 November 2003.

[23] F. Campos, et al., "An Extended Approach of DempsterShafer Theory", IEEE Explore, April 2009.

[24] T. Garma, et al., "Vision and RFID data fusion for tracking people in crowds by a mobile robot", Comput. Vis. Image Understand.(2010), doi:10.1016/j.cviu.2010.01.008

[25] S. Kundu, S. Chowdhury, S. Bhattacharyaa (2016) "Analyzing Different Features of Artificial Neural Networks and Its Applications In Different Fields".

[26] S. N. Sivanandam, S. Sumathi, S.N. Deepa "Introduction to Neural Network", Tata McGraw Hill.

[27] D. Hush, B. Horne (Jan. 1993) Progress in supervised neural networks: "what's new since Lippman?", IEEE Signal Processing Magazine, pp. 8-39

[28] http://www.mathworks.com/ Fuzzy Logic Toolbox user's guide. 